\title{
FUNDEF VERSUS FUNDEB: UMA ANÁLISE INTRODUTÓRIA SOBRE AS CONTINUIDADES E AS DESCONTINUIDADES DA POLÍTICA DE VALORIZAÇÃO DOCENTE
}

\author{
Géssica Priscila RAMOS ${ }^{1}$
}

\begin{abstract}
RESUMO: O objetivo desse trabalho é realizar uma investigação introdutória e comparativa entre o FUNDEF e o FUNDEB, por meio de análise documental e bibliográfica, sinalizando semelhanças e diferenças fundamentais entre suas inerentes políticas de valorização docente. Tal pesquisa verificou que, apesar de na sigla "FUNDEF" ficar sugerida uma ideia de valorização do grupo dos profissionais da educação (o magistério), em suas regulamentações e orientações, o MEC explicitou uma concepção de valorização individualizante, cuja prática pautar-se-ia na associação entre valorização e mérito. O objetivo central seria possibilitar aos estados e municípios um mecanismo de estímulo externo constante para que o sujeitoprofessor (desvalorizado pelo contexto mais amplo) se tornasse ou continuasse produtivo, garantindo o funcionamento eficiente do ensino. Atualmente com o FUNDEB, vê-se definir uma valorização legal que avançou no sentido de induzir o estabelecimento de um Piso Salarial Nacional, melhoria no funcionamento dos Conselhos locais, verbas para "capacitação" docente desvinculadas das verbas voltadas para a sua remuneração etc. Contudo, ainda predomina a ideia de se "capacitar" professores sem se fazer amplos investimentos - utilizando-se da modalidade a distância como estratégia principal -, e de meritocracia como estratégia para as ações de valorização docente, parecendo manter-se o pressuposto de que o professor ainda é responsável principal pelos problemas de qualidade do ensino brasileiro.
\end{abstract}

PALAVRAS-CHAVE: Valorização docente. FUNDEF. FUNDEB.

Durante meados da década de 90, no Brasil, o campo educacional recebeu grande destaque político, passando por um momento de profunda efervescência reformadora. Tal período iniciou aquilo que fora oficialmente chamado de "Década da Educação”, salientando a importância política que a questão educacional ilustrava naquele momento.

Renovar a qualidade do ensino foi a meta destacada, ocasionando várias medidas oficialmente tomadas nesse sentido. Os problemas do ensino brasileiro, notadamente focados no ensino fundamental, foram avaliados como problemas de qualidade, especialmente da qualidade do processo pedagógico que se efetivava nas salas de aula e que sustentaria, nesses termos, os altos índices de evasão e de repetência escolar no país. Por isso, modificar essa realidade, segundo a tônica da época, implicaria investir no profissional da sala de aula, ou seja, investir no professor.

\footnotetext{
${ }^{1}$ UNESP - Universidade Estadual Paulista. Instituto de Biociências, Letras e Ciências Exatas - Departamento de Educação. São José do Rio Preto - SP - Brasil. 15054-000 -gessicaramos@yahoo.com.br
} 
A partir de uma análise bibliográfica e documental sobre o período, é possível notar que essa intensa focalização sobre o professor ocorreu fundamentalmente por meio de políticas de Fundos. Assim, se no governo Fernando Henrique o FUNDEF (Fundo de Manutenção e Desenvolvimento do Ensino Fundamental e Valorização do Magistério) podia ser destacada como uma de suas políticas centrais no sentido de operacionalizar uma política de valorização docente, no governo Lula, o FUNDEB (Fundo de Manutenção e Desenvolvimento da Educação Básica e Valorização dos Profissionais da Educação) veio assumir tal papel. Mas seria possível afirmar, então, que há entre esses governos uma unicidade em termos da valorização docente proposta por seus diferentes Fundos?

Com base nessa questão, o objetivo deste trabalho é realizar uma análise introdutória e comparativa entre esses dois Fundos, sinalizando semelhanças e diferenças fundamentais que aproximam e afastam suas inerentes políticas de valorização docente.

\section{O governo Fernando Henrique Cardoso}

Desde a campanha eleitoral de Fernando Henrique Cardoso, passando por seus dois mandatos, o tema educacional sempre foi destacado como uma das prioridades de seu governo e do país. Conforme o discurso oficial, a educação seria o grande vetor de transformação e desenvolvimento da sociedade, o que justificaria tê-la como prioridade.

Alcançar esse grau de desenvolvimento, segundo o presidente, exigiria certa focalização no ensino fundamental, mais especificamente na questão de sua qualidade, visto que, de acordo com a interpretação oficial, os maiores problemas educacionais seriam o da evasão e o da repetência, associados ao desperdício de verbas.

Nessa perspectiva, a baixa qualidade na educação passou a ser tratada sob um enfoque setorial: o tipo de funcionamento do setor educacional começou a ser interpretado como causa e solução dos entraves educacionais. Com o obscurecimento da questão da redução dos investimentos em educação e o relevo dado tão somente à prioridade educacional no desenvolvimento do país, o tema dos problemas educacionais passou a ser discutido, no plano oficial, fora de um contexto interpretativo mais amplo, de tal modo que a relação entre a valorização docente e a qualidade do ensino fosse estabelecida aí sob bases economicistas.

Desse modo, o aspecto qualitativo da educação começou a ser abordado pela ótica da chamada "qualidade-produtiva", resumidamente definida pela eficiência do desempenho docente no rendimento escolar do aluno. Os problemas da qualidade do ensino (vistos como problemas de eficiência do ensino) começaram a ser transpostos de uma discussão pública, 
estrutural, política e estatal para uma discussão estritamente pedagógica, técnica, metodológica, escolar e administrativa, provenientes da má formação docente, da falta do uso de metodologias de ensino adequadas, da falta de fiscalização popular e da ineficiente gestão e financiamento da escola pela União, que supostamente gastaria bastante com educação, mas de forma não focalizada e de modo ineficiente.

O diagnóstico era o de que o país não gastava pouco com educação, mas que gastava mal e de que o problema educacional não era o da universalização do ensino, mas o da produtividade do trabalho escolar. Como estratégias, para tanto, ficou definido que, em termos de eficiência, seria necessário transferir responsabilidades para estados e municípios e incorporar os pais e a comunidade como fiscalizadores da escola; em termos de qualidade do ensino, o caminho privilegiado foi o da focalização dos aspectos pedagógicos e do trabalho do professor. Tal focalização, na prática, passou a justificar, nos discursos oficiais, as ações de valorização docente desenvolvidas nesse governo.

Nesse sentido, recebe destaque a ação "FUNDEF”, da qual, dentro do discurso de Fernando Henrique, passou a ser divulgada como o "Fundo de Valorização do Professor”, colocando em segundo plano, também em termos discursivos, seu objetivo estratégico de redistribuição de funções para a manutenção e o desenvolvimento do ensino fundamental entre as instâncias federadas.

\section{A valorização docente no Fundef}

Inicialmente, vale destacar que, em termos legais, o tema da valorização docente no FUNDEF remete tanto para a análise da Emenda Constitucional 14/96 (que criou o Fundo), quanto da Lei 9.424/96 (que regulamentou o Fundo). A partir da análise dessas legislações, é possível verificar que a ideia de valorização oficialmente construída moldou-se numa vertente individualizadora e meritocrática, segundo a abordagem feita dos temas remuneração, formação, Plano de Carreira e conselhos.

\section{A remuneração}

Ficou estabelecido que pelo menos 60\% dos recursos do Fundo destinavam-se à remuneração dos profissionais do magistério em efetivo exercício de suas atividades no ensino fundamental público. Todavia, vale destacar que, nem a Emenda, nem a Lei estabeleceram um piso salarial fixo para o magistério, permitindo a oscilação dos salários dos 
professores, segundo a definição dos pisos salariais estabelecidos pelas instâncias municipal e estadual. Ainda, a palavra remuneração, utilizada na Lei, implicava que a valorização financeira do magistério não passaria necessariamente pela questão salarial, mas pela questão de pagamento, que poderia ser efetivado por meio de recompensa, prêmio, gratificação, honorário, ordenado ou salário, tal como ficou implícito na amplitude do significado da palavra usada (RAMOS, 2008). Outro ponto a ser destacado é que a palavra remuneração foi associada à expressão condigna, que se refere ao merecimento, à proporcionalidade, ao mérito do profissional, centrando-se mais na valorização do profissional do que da profissão docente. O termo condigno (sinônimo de "proporcional ao mérito" e "merecido”), associado na Lei à palavra remuneração, pressupunha a existência de méritos diferenciados no magistério, a serem medidos conforme os critérios de desempenho, de iniciativa de formação e de dedicação exclusiva previstos nos Planos de Carreira. Assim, focando mais o professor do que a profissão magistério, a concepção legal de docente, em termos de remuneração, aproximava-se mais do seu caráter individual do que do coletivo, privilegiando mais a pessoa (e, conseqüentemente, o tão criticado “isolamento docente”!), isto é, suas capacidades, suas competências, seus méritos, seu empenho, sua "responsabilidade” etc., do que a atuação, o potencial, a mobilização, a divisão de problemas, a ajuda mútua, a força coletiva etc. de seu grupo.

\section{A formação}

Embora a formação não tenha sido tomada diretamente como política de valorização do magistério na Emenda 14, a capacitação foi lembrada pela Lei de regulamentação do FUNDEF - Lei 9.424/96. Nela, ficou estabelecido que, nos primeiros cinco anos de funcionamento do Fundo, parte dos recursos da parcela de 60\% destinados à remuneração do magistério poderia ser utilizada para a capacitação de professores leigos, segundo a formação exigida nos Novos Planos de Carreira e Remuneração do Magistério para a atuação desses profissionais. Contudo, vale frisar que, ao fazer uso especificamente do termo “capacitação”, a Lei transferiu o foco da questão da formação do magistério para a capacidade do profissional, de modo que os profissionais da educação “falhassem” mais pela falta de capacidade do que de formação. Nessa perspectiva, tal análise direcionava, novamente, o aspecto da valorização mais para a esfera do profissional-pessoa do que para a do grupo. 


\section{O Plano de Carreira}

Os Planos de Carreira e Remuneração do Magistério apareceram como veículo para a valorização do magistério, sendo uma das exigências de implementação do FUNDEF. Assim, o item Plano de Carreira e Remuneração do Magistério revelava a preocupação com a existência de um profissional que tivesse regras para progressão na carreira. Entretanto, vale destacar que, ainda que se considere o peso positivo dessa iniciativa legal, conforme a Resolução $n^{\circ}$ 3/97 do CNE, essas regras usualmente se ligavam às avaliações de desempenho e de conhecimentos curriculares e pedagógicos, utilizadas como critérios para a mensuração do profissional. Essas regras eram definidas de acordo com os parâmetros de qualidade estabelecidos no âmbito de cada instância federada. De tal modo, tais iniciativas também acenavam para uma prática de valorização individualizada, focada no mérito docente alcançado nos processos de avaliação e pautada nas possibilidades (e vontades) locais.

\section{O Conselho}

Ficou estipulado que cada instância envolvida com o FUNDEF deveria instituir um conselho de acompanhamento e controle social do fundo. Esses Conselhos seriam instituídos nas três instâncias federais, no prazo de cento e oitenta dias contados pela vigência da Lei 9.424/96. A composição do Conselho variaria em número de conselheiros e órgãos representados de acordo com a esfera nacional de atuação. Apesar disso, cabe salientar que o Conselho não foi destacado em momento algum como item da política de valorização do magistério, causando a impressão de uma concepção de valorização distanciada do colegiado. Tal fato, novamente, deslocava a questão da valorização do grupo para o profissional-pessoa.

\section{O governo Lula}

Finalizado os oito anos de governo de Fernando Henrique Cardoso, a eleição de Luiz Inácio Lula da Silva, em 2002, veio mostrar o fracasso do modelo político e político educacional economicista (SADER, 2002; FRIGOTTO; CIAVATTA, 2003) perante a sociedade. Entretanto, apesar de tantas expectativas, alguns autores (BRAMI-CELENTANO; CARVALHO, 2007; MARQUES; MENDES, 2007; OLIVEIRA, 2006) avaliam que o governo Lula ainda não conseguiu deixar claro os limites e as diferenças existentes entre sua matriz política e a do governo Fernando Henrique, realizando políticas educacionais 
insuficientes para atuar nos objetivos da valorização docente e da qualidade do ensino, mantendo um diálogo estreito com o setor empresarial (SAVIANI, 2007).

Seguindo essa avaliação é possível constatar que os temas “educação”, “professor” e “ensino fundamental” praticamente ficaram esquecidos no primeiro mandato do governo Lula, mantendo-se movidos pelas políticas educacionais do governo anterior. Nesse mandato, foram privilegiadas pelo governo Lula fundamentalmente políticas de ações afirmativas e voltadas para o ensino superior, como: cotas, PROUNI etc. Vale destacar ainda que a reforma do ensino superior também apareceu como preocupação destacada nesse contexto.

Destarte, é possível afirmar que foi somente no final do primeiro mandato que um importante instrumento de focalização da educação básica, também voltado para a valorização docente, começou a ser intensamente discutido: o FUNDEB.

A aprovação desse Fundo ocorreu apenas no segundo mandato de Lula, em 2007, sob a Lei 11.494, com sua reeleição. Nessa Lei, o tema da valorização docente foi novamente resgatado, contudo, agora, abrangendo os profissionais de toda a educação básica.

\section{A valorização docente no Fundeb}

Inicialmente, vale destacar que, em termos legais, o tema da valorização docente no FUNDEB remete tanto para a análise da Emenda Constitucional n. 53 de 19 de dezembro de 2006, que o institui, e da Lei 11.494/07, que o regulamenta. A partir da análise dessas legislações, é possível verificar que a proposta de valorização oficialmente construída nele apresenta alguns avanços em relação às definições realizadas pelo FUNDEF, especialmente pelo fato de ela se voltar para os professores de toda a educação básica e não mais apenas para os docentes do ensino fundamental. Entretanto, uma analisa mais atenta consegue verificar que, não obstante os avanços, essas políticas ainda mantém várias continuidades.

\section{A remuneração}

Pela Lei 11.494/2007 ficou definida a exigência de que no mínimo 60\% do Fundo fossem destinados à remuneração dos profissionais da educação básica. No FUNDEB, o termo remuneração continuou sendo usado na legislação em detrimento da palavra salário. Contudo, diferentemente do FUNDEF, ficou estabelecido pelo novo Fundo que o citado percentual não poderia ser usado para capacitação de professores, ainda que esses fossem leigos. A Lei definiu que os gastos com capacitação deveriam ser contabilizados do montante 
dos $40 \%$ das verbas restantes. Grande passo ainda foi dado pelo FUNDEB com a sinalização da criação do Piso Salarial Nacional para o professor da educação básica, antiga bandeira do setor educacional. Tal piso, previsto pelo Fundo, foi regulamentado em 2008 pela Lei 1.738. Com ela ficou estipulado o piso salarial de R $\$ 950,00$ para o profissional com formação mínima em nível médio, na modalidade normal, e carga horária de 40 horas semanais.

\section{A Formação}

O termo capacitação também foi usado pelas legislações do FUNDEB em detrimento da palavra formação. Conforme destacado anteriormente, foi definido que, para a capacitação, deveriam ser utilizadas as verbas referentes aos $40 \%$ - não destinadas à remuneração dos profissionais da educação. Todavia, vale frisar que, na prática, a maior parte das ações do governo federal voltadas para o objetivo da capacitação docente se remete aos programas de educação a distância, extra FUNDEB, como: UAB (Universidade Aberta do Brasil); ProLicenciatura; Pro-Infantil; Pro-Letramento; etc..

\section{Os Planos de Carreira}

Também no FUNDEB foi mantida a exigência legal de criação de Planos de Carreira e Remuneração do Magistério por parte dos estados e municípios, inclusive com a incorporação do valor do piso salarial pela Lei 1.738/08, até o prazo de dezembro de 2009. Contudo, continuou valendo como documento de fundamentação para criação desses documentos a Resolução n 3/97 do CNE, e suas orientações quanto à ligação da remuneração a critérios como avaliações de desempenho e de conhecimentos curriculares e pedagógicos.

\section{Os Conselhos}

O conselho também não foi focado pelo FUNDEB como veículo de valorização docente. Contudo, o FUNDEB deu um grande passo para o seu funcionamento mais democrático nas localidades, ao definir que: os membros do Conselho deveriam ser indicados pelos segmentos que representam (pares/sindicatos); o presidente do Conselho deveria ser eleito pelos próprios conselheiros em reunião do colegiado; a função de presidente não deveria ser exercida pelo representante da Secretaria de Educação ou qualquer outro representante do governo gestor, objetivando barrar possíveis perseguições de conselheiros 
via faltas injustificadas, exoneração ou demissão sem justa causa, afastamento injustificado e involuntário do Conselho; os membros do Conselho deveriam contar com apoio em suas capacitações por parte do MEC.

\section{Avaliação Geral}

A partir dessa análise inicial é possível se afirmar que, ainda que na sigla FUNDEF (Fundo de Valorização e Desenvolvimento do Ensino Fundamental e Valorização do Magistério), ficasse sugerida uma ideia de valorização do grupo dos profissionais da educação (o magistério), em suas regulamentações e orientações, o MEC deixou explicitada uma concepção de valorização individualizante, cuja prática (em estados e municípios) pautar-se-ia numa proposta que associava valorização e mérito. O objetivo central parecia ser o de possibilitar aos estados e municípios um mecanismo de estímulo externo constante para que o sujeito-professor (desvalorizado pelo contexto mais amplo) se tornasse ou continuasse produtivo, garantindo o funcionamento eficiente do ensino.

Atualmente com o FUNDEB, vê-se definir uma valorização legal que avançou no sentido de induzir o estabelecimento de um Piso Nacional, melhoria nas garantias de funcionamento dos Conselhos locais, verbas para “capacitação” docente desvinculadas das verbas voltadas para a sua remuneração etc. Contudo, apesar desses avanços, ainda predomina, nesse governo, a ideia de se “capacitar” professores sem se fazer amplos investimentos - utilizando-se da modalidade a distância como estratégia principal -, e de meritocracia como estratégia associada às ações de valorização docente - via Planos de Carreira, por exemplo -, parecendo manter-se o pressuposto de que o professor ainda é responsável principal pelos problemas de qualidade do ensino brasileiro.

\section{FUNDEF AGAINST FUNDEB: AN INTRODUCTORY ANALYSIS ON THE CONTINUITIES AND THE DESCONTINUIDADES OF THE TEACHER VALORIZATION POLITICS}

ABSTRACT: The objective of this article is to accomplish an introductory and comparative investigation between FUNDEF and FUNDEB, through documental and bibliographical analysis, signaling fundamental likeness and differences among your inherent teacher valorization politics. This research verified that, in spite of in the acronym " FUNDEF " to be suggested an idea of valorization of the education professional group (the teachers), in your regulations and orientations, the MEC showed a conception of individual valorization, whose 
practice would associate valorization and merit. The central objective would be to make possible to the states and municipal districts a mechanism of constant external incentive so that the subject-teacher (depreciated by the wider context) turned himself or continued productive, guaranteeing the teaching efficient. Now with FUNDEB, it sees to define a legal valorization that it moved forward to induce the establishment of a National Wage Base, improvement in the operation of the local Council, budgets for teachers "training" disentailed of the budgets for him remuneration etc. However, the idea still prevails of teachers "training" without doing wide investments - using of the distance teaching modality as main strategy -, and of meritocracy as strategy to the actions of teacher valorization, seeming to maintain the presupposition that the teacher is still main responsible for the quality problems of the Brazilian teaching.

KEYWORDS: Teacher Valorization. FUNDEF. FUNDEB.

\section{REFERÊNCIAS}

BRAMI-CELENTANO, A.; CARVALHO, C. E. A reforma tributária do governo Lula: continuísmo e injustiça fiscal. Revista Katálysis, Florianopólis, v.10, n.1, p. 44-53, 2007.

BRASIL. Constituição (1988). Emenda Constitucional no 14, de 12 de setembro de 1996. Modifica os artigos 34, 208, 211 e 212 da Constituição Federal e dá nova redação ao artigo 60 do Ato das Disposições Constitucionais Transitórias. Diário Oficial da União, Brasília, 13 set. 1996a.

. Lei n ${ }^{\circ}$ 9.424, de 24 de dezembro de 1996. Dispõe sobre o Fundo de Manutenção e Desenvolvimento do Ensino Fundamental e Valorização do Magistério. Diário Oficial da União, Brasília, 26.dez. 1996b.

Constituição (1988). Emenda Constitucional n 53, de 19 de dezembro de 2006. Dá nova redação aos arts. $7^{\circ}$, 23, 30, 206, 208, 211 e 212 da Constituição Federal e ao art. 60 do Ato das Disposições Constitucionais Transitórias. Diário Oficial da União, Brasília, 20.dez. 2006.

Lei $n^{\circ}$ 11.494, de 20 de junho de 2007. Regulamenta o Fundo de Manutenção e Desenvolvimento da Educação Básica e de Valorização dos Profissionais da Educação FUNDEB, de que trata o art. 60 do Ato das Disposições Constitucionais Transitórias; altera a Lei ${ }^{\circ}$ 10.195, de 14 de fevereiro de 2001; revoga dispositivos das Leis $n^{\circ} 9.424$, de 24 de dezembro de 1996, 10.880, de 9 de junho de 2004, e 10.845, de 5 de março de 2004; e dá outras providências. Diário Oficial da União, Brasília, 21 jun. 2007a.

Ministério da Educação. Plano de Desenvolvimento da Educação [PDE]. 2007b. Disponível em: <http://portal.mec.gov.br/pde>. Acesso em: 15 set. 2008.

Ministério da Educação. O Plano de Desenvolvimento da Educação: razões, princípios e programas. 2007c. Disponível em: <http://portal.mec.gov.br/arquivos/pdf/livromiolov4.pdf>. Acesso em: 15 set. 2008. 
Presidência da República. Palavra do presidente: Fernando Henrique Cardoso. Brasília: Presidência da República, 2002. v.01-16.

FRIGOTTO, G; CIAVATTA, M. Educação básica no Brasil na década de 1990: subordinação ativa e consentida à lógica do mercado. Educação e Sociedade, Campinas, v.24, n.82, p.93130, abr. 2003.

MARQUES, R M; MENDES, A. Servindo a dois senhores: as políticas sociais no governo Lula. Revista Katálysis, Florianópolis, v. 10, n.1, p.15-23, 2007.

OLIVEIRA, F de. O Momento Lênin. Novos Estudos CEBRAP, São Paulo, n.75, p.23-47, 2006.

RAMOS, G P. Entre a proposta e o pretexto da qualidade do ensino: uma leitura sobre os liames da valorização docente a partir do FUNDEF. 2008. 311f. Tese (Doutorado em Educação) - Centro de Educação e Ciências Humanas, Universidade Federal de São Carlos , São Carlos, 2008.

SADER, E S. O significado da vitória de Lula. Pt em Movimento, 2002. p.08.

SAVIANI, D. O Plano de Desenvolvimento da Educação: análise do projeto do MEC. Educação e Sociedade, Campinas, v.28, n.100, p.1231-1255. out. 2007.

\section{BIBLIOGRAFIA CONSULTADA}

BRASIL. Decreto Presidencial n 6.094, de 24 de abril de 2007. Dispõe sobre a implementação do Plano de Metas Compromisso Todos pela Educação, pela União, em regime de colaboração com Municípios, Distrito Federal e Estados. Diário Oficial da União, Brasília, 25 abr. 2007.

DIAS-DA-SILVA, M. H. G. F. O professor e seu desenvolvimento profissional: superando a concepção do algoz incompetente. Cadernos Cedes, Campinas, v 19, n. 44, p.33-45, abr. 1998.

GARCIA, R L. Professoras do Brasil- algozes ou vítimas? In: ENCONTRO NACIONAL DE DIDÁTICA E PRÁTICA DE ENSINO - FORMAÇÃO E PROFISSIONALIZAÇÃO DO EDUCADOR, 8., 1996, Florianópolis. Anais... Florianópolis: ENDIPE, 1996. v.2. p.147-159

MELLO, E. M. B. Política de (des)valorização e (des)profissionalização do magistério público: vieses atuais. In: SIMPÓSIO BRASILEIRO DE POLÍTICA E ADMINISTRAÇÃO DA EDUCAÇÃO, 23.; CONGRESSO LUSO-BRASILEIRO DE POLÍTICA E ADMINISTRAÇÃO DA EDUCAÇÃO, 5.; COLÓQUIO IBERO-AMERICANO DE POLÍTICA E ADMINISTRAÇÃO: POR UMA ESCOLA DE QUALIDADE PARA TODOS: FORMAÇÃO, FINANCIAMENTO E GESTÃO DA EDUCAÇÃO, 2007, Porto Alegre. 
Anais... Porto Alegre, 2007. Disponível em: <http://www.isecure.com.br/anpae/index2.html>. Acesso em: 20 out. 2008. .

MONLEVADE, J A C. de. Valorização salarial dos professores: o papel do piso salarial profissional nacional como instrumento de valorização dos professores de Educação Básica Pública. 2000. 307f. Tese (Doutorado em Educação) - Faculdade de Educação, Universidade Estadual de Campinas, Campinas, 2000.

SHIROMA, E. O.; MORAES, M. C. M. de.; EVANGELISTA, O. Política educacional. Rio de Janeiro: DP\&A, 2000. 